\title{
Current State of Affairs With Regard to Thanatological Imaging in Francophone Sub-saharan Africa: Opinions of Radiology Technicians
}

\author{
Abdoulatif Amadou ${ }^{1,2^{*}}$, Pihou Gbande ${ }^{2}$, Solim Carolle Nabede ${ }^{2}$, Massaga Dagbe ${ }^{4}$, Lantam Sonhaye ${ }^{2}$, Lama Kedigom Agoda-Koussema ${ }^{5}$ \\ and Komlanvi Adjenou ${ }^{2}$
}

*Correspondence: amadoulatif@yahoo.fr

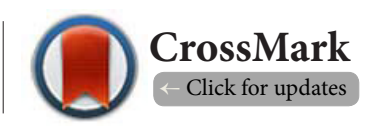

\begin{abstract}
'Radiology department of Centre Hospitalier Régional Tomdè, Kara, Togo.
${ }^{2}$ Radiology department of Centre Hospitalier Universitaire Campus, Lomé, Togo.

${ }^{3}$ Radiology department of Centre Hospitalier Régional deSokodé, Togo.

${ }^{4}$ Radiology department of Centre Hospitalier Universitaire de Kara, Togo.

${ }^{5}$ Radiology department of Centre Hospitalier UniversitaireSylvanus Olympio, Togo.
\end{abstract}

\begin{abstract}
Background: In French-speaking sub-Saharan Africa, thanatological imaging is not integrated into the training of radiology technicians. Thus, this raises a question about the knowledge level of radiology technicians in this field.

Purpose: To evaluate the knowledge level of radiology technicians in thanatological imaging in Frenchspeaking sub-Saharan Africa.

Materiel and Methods: This is a five-month descriptive cross-sectional study carried out in thirteen French-speaking countries in sub-Saharan Africa among radiology and medical imaging technicians. The questionnaires were completed in two formats: electronic format (online via Google Forms) and print format.

Results: We included 154 technicians in our study. The mean age was 37.83 years. The majority of technicians were male (71.4\%). Of these radiology technicians, $81.2 \%$ had some knowledge of postmortem imaging, while only $11.7 \%$ had training in postmortem imaging. Technicians who had already been called upon to perform a postmortem radiology examination represented $30.6 \%$. Plain radiography (X-ray) was the most performed imaging test (55.3\%) followed by X-ray coupled with CT scan (23.4\%). According to 35\% of technicians, their radiology and medical imaging department carried out a postmortem examination at least once a year. Access to imaging service was granted on request when needed in $34 \%$ of cases. The reluctance of the technicians was the main obstacle to carrying out the examination.
\end{abstract}

Conclusion: Although known to technicians, thanatology is very rarely practiced in French-speaking subSaharan Africa. Plain radiography is the most common examination.

Keywords: Thanatology imaging, French-speaking, Sub-Saharan Africa, Radiology technicians

\section{Introduction}

Thanatology, also called "virtual autopsy" entails the use of different medical imaging techniques (computed tomography, magnetic resonance imaging, angiography) in postmortem examination [1]. This technology, were used in forensic medicine very soon after the introduction of $\mathrm{X}$-rays in medicine $[2,3]$. However, it was not until the introduction of the CT scan, and in particular the multidetector CT scan, that a real radiological revolution in forensic medicine began [4]. It is now an effective tool in the study of criminal acts or unexplained deaths by providing essential information necessary for drawing conclusions in complex cases (charred bodies, rotten bodies, identification) [1]. CT scan, allows for three-dimensional reconstructions, which offers clear advantages in explaining complex medical data to people from other fields [5]. His expertise is essential to provide the radiologist with a quality examination result for the purpose 
Amadou et al., Medical Imaging and Radiology 2021,

http://www.hoajonline.com/journals/pdf/2054-1945-9-2.pdf

doi: 10.7243/2054-1945-9-2

of diagnosing the cause and manner of death. His role as a coordinator in carrying out examinations makes him one of the centerpieces of thanatological imaging [1]. However, in French-speaking sub-Saharan Africa, thanatological imaging is not integrated into the training of radiology technicians. Thus, this raises a question about the knowledge level of radiology technicians in this field. Thanatological imaging studies are rare in French-speaking sub-Saharan Africa. This motivated this work, the general objective of which was to assess the knowledge level of radiology technicians in thanatological imaging.

\section{Materials and methods}

Our study is an opinion survey covering a period of 5 months, from $20^{\text {th }}$ April 2020 to $20^{\text {th }}$ September 2020, and carried out in 13 French-speaking countries of sub-Saharan Africa (Benin, Burkina-Faso, Burundi, Cameroon, Côte d'Ivoire, Gabon, Guinea, Mali, Madagascar, Niger, Senegal, Chad and Togo). The study population consisted of radiology and medical imaging technicians working in French-speaking sub-Saharan Africa.

The investigation consisted in designing a questionnaire in two formats: a physical copy and a digitalcopy via Google Forms. The questionnaires were sent to radiology technicians in the countries concerned. The physical questionnaire was sent to and completed manually by national technicians and the digital one was emailed to international technicians.

The data collected included socio-demographic and professional data, perception and level of knowledge of thanatology. The data was then entered in Google Sheets and then transferred into Epilnfo version 7.2 and into Microsoft Excel 2019 spreadsheet which we used to produce pivot tables with graphics. The text was written using Microsoft Word 2019 software and the references were generated using Zotero.

\section{Results}

We distributed 275 questionnaires to radiology technicians in French-speaking sub-Saharan Africa and obtained 154 responses, representing a participation rate of $56 \%$. The mean age of the technicians was 37.83 years with extremes of 23 and 68 years. 110 technicians (71.4\%) were male with a male/ female sex ratio of 2.5. Forty-five (45) technicians representing $29.2 \%$ of responders were in Togo (Figure 1 ).

Technicians with 5 to 10 years of professional experience represented $33.8 \%$ ( $n=52)$, followed by those with less than 5 years of experience, representing $22.8 \%(n=35)$. The majority of technicians i.e. $68.3 \%(n=106)$ worked in the public sector. Technicians with knowledge of postmortem imaging represented $81.2 \%(n=125)$.

Postmortem examinations were performed in the radiology departments of $30.5 \%(n=47)$ of the technicians (Table 1$)$. There was no specific unit dedicated to postmortem imaging in the radiology departments of $98 \%(n=151)$ of technicians. Madagascar, Mali and Senegal were the only countries that had a dedicated postmortem imaging unit.

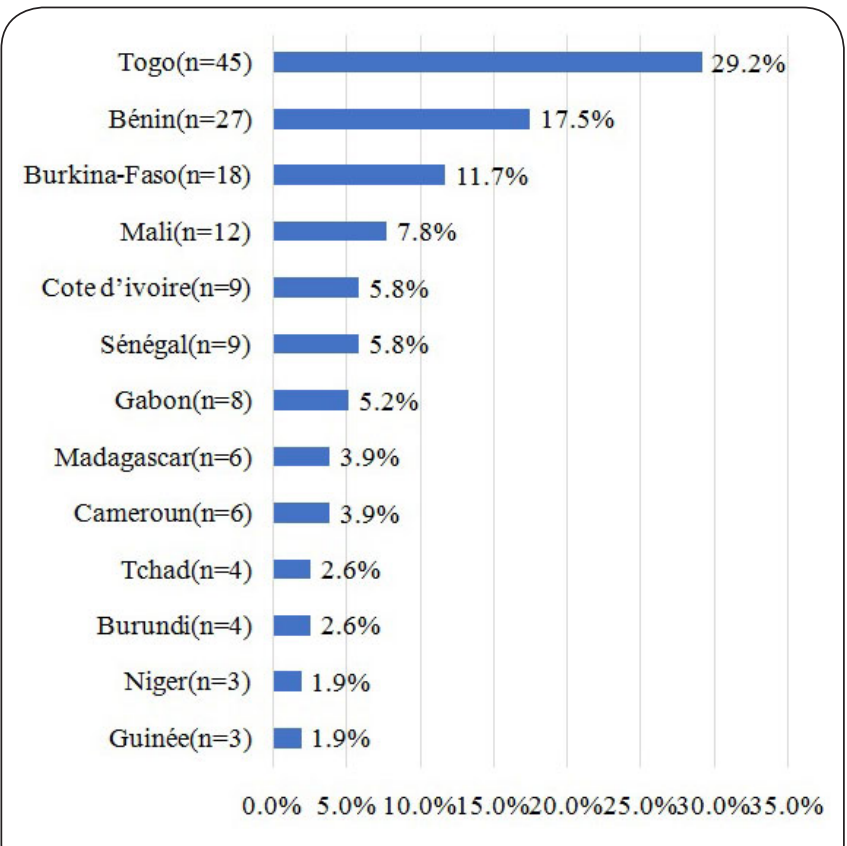

Figure 1. Distribution of technicians by country of practice.

Table 1. Distribution of the performance of postmortem examinations by country.

\begin{tabular}{lllllll}
\hline & NO & \multicolumn{3}{l}{ YES } & \multicolumn{3}{l}{ Total } \\
\cline { 2 - 7 } & $\mathbf{N}$ & $\mathbf{\%}$ & $\mathbf{N}$ & $\mathbf{\%}$ & $\mathbf{N}$ & $\%$ \\
\hline Benin & 26 & 16.9 & 1 & 0.6 & 27 & 17.5 \\
Burkina Faso & 11 & 7.1 & 7 & 4.5 & 18 & 11.7 \\
Burundi & 3 & 1.9 & 1 & 1.0 & 4 & 2.6 \\
Cameroon & 2 & 1.3 & 4 & 2.6 & 6 & 3.9 \\
Cote d'Ivoire & 3 & 1.9 & 6 & 3.9 & 9 & 5.8 \\
Gabon & 3 & 1.9 & 5 & 3.2 & 8 & 5.2 \\
Guinea & 3 & 1.9 & 0 & 0.0 & 3 & 1.9 \\
Madagascar & 5 & 3.2 & 1 & 0.6 & 6 & 3.9 \\
Mali & 7 & 4.5 & 5 & 3.2 & 12 & 7.8 \\
Niger & 3 & 1.9 & 0 & 0.0 & 3 & 1.9 \\
Senegal & 7 & 4.5 & 2 & 1.3 & 9 & 5.8 \\
Tchad & 0 & 0.0 & 4 & 2.6 & 4 & 2.6 \\
Togo & 34 & 22.1 & 11 & 7.1 & 45 & 29.2 \\
Total & $\mathbf{1 0 7}$ & $\mathbf{6 9 . 5}$ & $\mathbf{4 7}$ & $\mathbf{3 0 . 5}$ & $\mathbf{1 5 4}$ & $\mathbf{1 0 0 . 0}$ \\
\hline
\end{tabular}

Only $30.6 \%$ ( $n=47$ ) of technicians had been called upon at least once to perform a postmortem radiology examination. Among the different imaging techniques, postmortem plain radiography (X-ray) was the most performed examination at a rate of $55.3 \%$ ( $n=85)$ followed by X-ray coupled with CT scan at a rate of $23.4 \%(n=36)$ (Figure 2). Postmortem imaging was performed at a frequency rate of at least 2 per year according to $35 \%$ of technicians (Figure 3 ).

Access to the imaging department was granted on request 


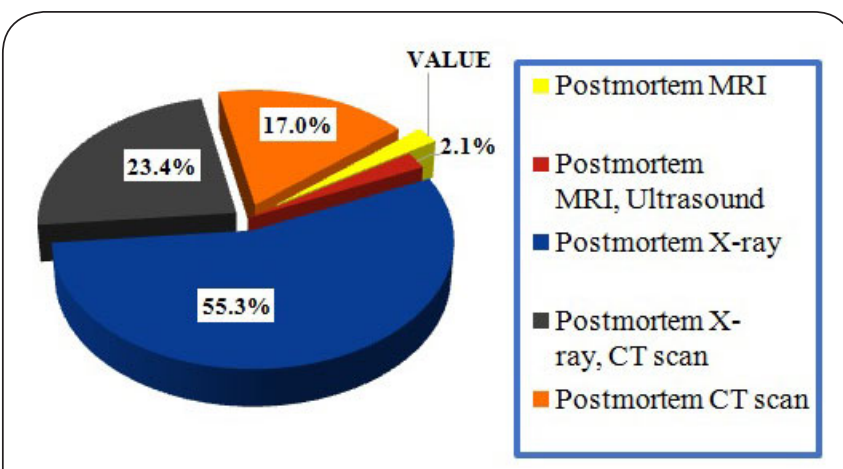

Figure 2. Distribution of technicians according to the type of examination carried out.

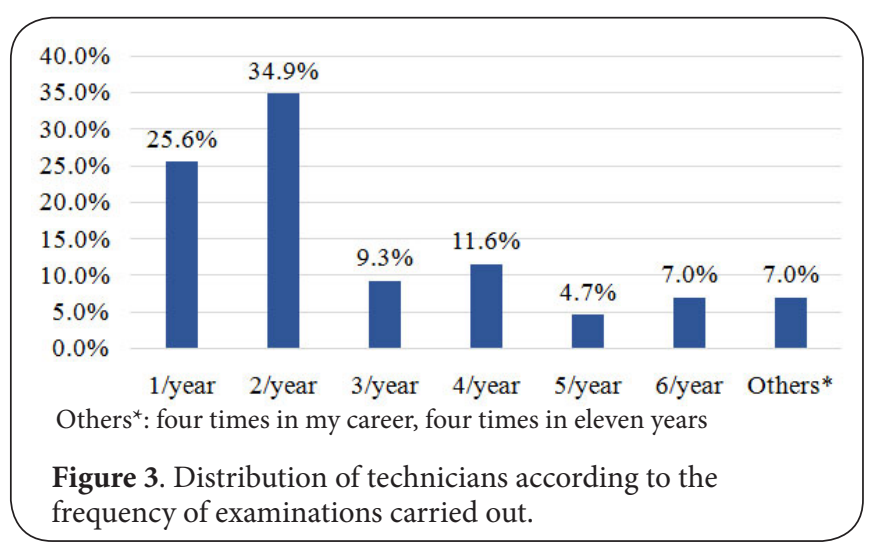

when needed or by agreement with the radiology department according to $34 \%$ and $29 \%$ of technicians, respectively (Figure 4).

The reluctance of the technicians and the unpleasant smell associated with the decomposing body are the main obstacles to performing postmortem imaging according to $29.2 \%$ and $14 \%$ of technicians, respectively.

The main solutions to enable carrying out postmortem imaging examinations would be the creation of a unit dedicated specifically to thanatological imaging according to $39.3 \%(n=35)$ of technicians, and sensitization of medical

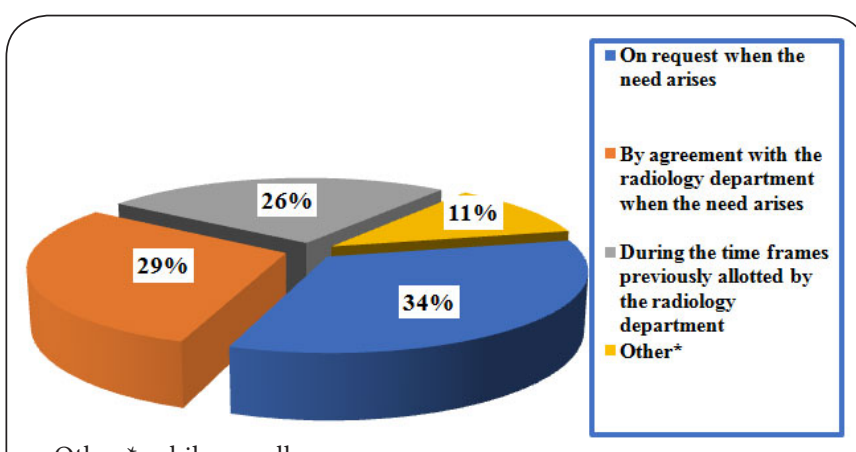

Other *: while on call

Figure 4. Distribution of technicians according to access to imaging service. staff according to $31.5 \%$. $(n=28)$ of them.

Thanatological imaging was performed on judicial requisition according to $24.7 \%(n=22)$ of technicians and for scientific purposes according to $3.4 \%(n=3)$ of them. The vast majority of technicians ( $n=136$, i.e. $88.3 \%$ ) had no training in postmortem imaging.

\section{Discussion}

Our data was collected from 13 countries after several reminders were sent to 25 countries of French-speaking sub-Saharan Africa, representing a proportion of $52 \%$.

In our study, $56.5 \%$ of technicians had less than 10 years of professional experience and the majority (63.8\%) worked in the public sector. On one hand, those figures were similar to those reported by some studies in Africa concerning radiology technicians $[6,7]$. On the other hand, in the study by Matar et al [8], the public sector represented $11 \%$.

In our survey, the percentage of respondents who were asked to perform a postmortem examination was $30.5 \%$ $(n=47)$. Our study found $81.2 \%$ of technicians with knowledge of thanatology. This level of knowledge is in contrast to the fact that $88.3 \%$ did not receive training in that field. It is also in contrast with the level of practice of thanatology by technicians in radiology departments, with only $30.6 \%$ of themhaving already performed a postmortem imaging examination.

We found that plain radiography (X-ray) was the most common imaging modality (55.3\%), followed by X-ray + CT scan (23.4\%) and CT scan (17.02\%). This result is contrary to that of Dumousset et al. in France who reported a predominance of postmortem CT scan (32.60\%), followed by CT scan + MRI (10.19\%) and MRI ( $n=1.2 \%$ ) [9]. In Africa, CT scan and MRI are hardly available in normal radiology practice. This explains why these investigations were not commonlyused in post mortem examinations. In addition, the lack of training of technical staff and radiologists in the interpretation of CT scans and postmortem MRI could explain the non-prescription of these examinations. Since standard X-ray is the most readily available test, it is obvious that it would be the most requested test.

In developed countries, postmortem CT scan and MRI have become almost routine, both in adult and pediatric practice, but also in anthropology, with CT scan and/or MRI machines even available within forensic institutes at times [6].

The frequency of performing postmortem imaging examinations in our study was at least 2 per year according to $35 \%$ of technicians. In the study by Dumousset et al. [9], $23.56 \%$ of centers performed at least 50 examinations per year and $5 \%$ performed more than 200 examinations per year. This finding exposes the lagging in French-speaking sub-Saharan Africa with respect to carrying out postmortem examinations. This is reflected in the lack of organization and imaging services specializing in thanatology, unlike in developed countries. In Africa, forensic medicine is in its infancy and does not facilitate conventional autopsies. Moreover, the unavailability of cross-sectional radiological equipment makes thanatological 
Amadou et al., Medical Imaging and Radiology 2021,

http://www.hoajonline.com/journals/pdf/2054-1945-9-2.pdf

doi: $10.7243 / 2054-1945-9-2$

imaging more difficult.

In our study, access to the imaging department was granted on request when needed or by agreement with the radiology department according to $34 \%$ and $29 \%$ of technicians, respectively. In the study by Dumousset et al. [9], access to the facility is granted in the morning before the livings are admitted (9.22\%) or in the evening when the program is over (34\%) or between 12 p.m. and 2 p.m. (4.10\%), on working days as well as on weekends and holidays in half of the cases.

In fact, since cross-sectional imaging sessions are carried out most often on devices intended for clinical care, it is important to avoid making patients come across dead bodies, which often implies scheduling these examinations outside working hours and this poses additional planningchallenges.

In our study, the challenges were mainly the reluctance of technicians (29.2\%), the lack of training and the unpleasant odor associated with the decomposing body (14\%). Dumousset et al. [9] encountered the same challenges, but also the lack of information from magistrates, the reluctance of courts to allow the release of funds, the scheduling of these examinations outside of clinical hours (machine time). Thanatological imaging thus poses many organizational problems. It presupposes excellent collaboration between the radiology and forensic medicine departments. This collaboration between the two imaging and forensic medicine services is therefore most often based on people and strong human ties. The active and enthusiastic involvement of medical radiology technicians is essential to the success and sustainability of this arrangement [9]. Thus, many practical issues arise concerning the accessibility of the machines and also the transport of corpses. The systematic use of transparentX-ray permeable body bags to isolate and wrap bodies to avoid any direct contact during handling and any risk of contamination of the room by biological fluids is not always sufficient to contain the odors of putrefaction, making any examination impossible, at least during working hours [10]. Successful completion of the examination implies on the one hand the availability of a morgue technician to transport the corpse, which may take a longer or a lesser time depending on the geographical configuration of the establishment, and on the other hand the motivation of the team of radiology technicians.

Regarding demand, $24.7 \%$ of technicians estimated that thanatological imaging was carried out on judicial requisition and $3.4 \%$ reported it was for scientific purposes. In the study by Garetier et al. [11], the examinations were requested by the public prosecutor on judicial requisition in consultation with the forensic doctor, according to his needs and working habits, as well as in possible partnership with the radiology department. For Dumousset et al. [9], the examinations were carried out on judicial requisition in $23.53 \%$ of cases and for scientific purposes in $19 \%$ of cases.

\section{Conclusion}

Thanatology is a new imaging specialty; although it is well known to radiology technicians, it is less practiced and less organized in Africa. Thanatological examination is most often done on judicial requisition. Plain radiography remains the most requested examination.

\section{Competing interests}

The authors declare that they have no competing interests.

Authors' contributions

\begin{tabular}{|l|c|c|c|c|c|c|c|}
\hline Authors' contributions & AA & PG & SCN & MD & LS & LA & KA \\
\hline Research concept and design & $\sqrt{ }$ & -- & -- & -- & -- & -- & -- \\
\hline Collection and/or assembly of data & $\sqrt{ }$ & $\sqrt{ }$ & $\sqrt{ }$ & $\sqrt{ }$ & -- & -- & -- \\
\hline Data analysis and interpretation & $\sqrt{ }$ & $\sqrt{ }$ & $\sqrt{ }$ & $\sqrt{ }$ & -- & -- & -- \\
\hline Writing the article & $\sqrt{ }$ & $\sqrt{ }$ & $\sqrt{ }$ & $\sqrt{ }$ & $\sqrt{ }$ & -- & -- \\
\hline Critical revision of the article & $\sqrt{ }$ & $\sqrt{ }$ & $\sqrt{ }$ & $\sqrt{ }$ & $\sqrt{ }$ & $\sqrt{ }$ & $\sqrt{ }$ \\
\hline Final approval of article & $\sqrt{ }$ & $\sqrt{ }$ & $\sqrt{ }$ & $\sqrt{ }$ & $\sqrt{ }$ & $\sqrt{ }$ & $\sqrt{ }$ \\
\hline Statistical analysis & $\sqrt{ }$ & $\sqrt{ }$ & $\sqrt{ }$ & $\sqrt{ }$ & -- & -- & -- \\
\hline
\end{tabular}

\section{Acknowledgments}

The author are grateful to radiology techniciansof French-speaking countries of sub-Saharan Africa for allowing us to undertake this research.

\section{Publication history}

Senior Editor: Domenico Rubello, Santa Maria della Misericordia Hospital, Italy.

Received: 25-Jun-2021 Final Revised: 10-Aug-2021

Accepted: 23-Sept-2021 Published: 06-Oct-2021

\section{References}

1. Lianes $P$, Loumagne $L$, Thibaut $C$, et al. L'autopsie virtuelle en TDM : complément de l'autopsie-rôle du manipulateur. J Rad. 2007;88:13531353

2. Brogdon BG. The scope of forensic radiology. Clin Lab Med 1998;18:203240

3. Hergan K,Kofler K,Oser W.Drug smuggling by boy packing:What radiologists should know about it. Eur Radiol 2004;14:736-742

4. Grabherr S, Lesta MDM, Rizzo E, et al. L'imagerie forensique. Rev Med Suisse 2008;4 :1609-1614

5. Farkash U,Scope A,Lynn M,et al.Preliminary experience with postmortem computed tomography in military penetrating trauma. J Trauma 2000;48:303-308

6. Mpinga EK, Chastonay P, Pelissier F, et al. Conflits en fin de vie : Perceptions des professionnels de santé en Valais Romand. Rech Soins Infirm 2016;3:96-107.

7. Essiben F, Foumane P, Moifo B, et al. Pratique de l'échographie de routine dans le suivi de la grossesse à Yaoundé (Cameroun) : analyse des connaissances des prescripteurs. Health Sci Dis 2016;17:548.

8. Matar M, Picone O, Dalmon C, et al. Évaluation des connaissances des échographistes sur les clichés d'échographie de dépistage du deuxième trimestre recommandés par le Comité technique national de l'échograpahie. J Gynecol Obstet Biol Reprod 2013;42:473-478.

9. Dumousset E, Souffron V, Macri F, et al. Imagerie postmortem en France : état des lieux en 2017.Diagn Interv Imaging2017;98:225-235.

10. Otal P, Dedouit F, Costagliola R, et al. Imagerie thanatologique : les problèmes organisationnels. J Rad 2005;86:1453-1453. 
Amadou et al., Medical Imaging and Radiology 2021,

http://www.hoajonline.com/journals/pdf/2054-1945-9-2.pdf

11. Garetier M, Deloire L, Dedouit F, et al. Imagerie tomodensitométrique post-mortem du suicide. Diagn Interv Imaging2017;4-5:204-216.

\section{Citation:}

Amadou A, Gbande P, Nabede SC, Dagbe M, Sonhaye L, Agoda-Koussema LK and Adjenou K. Current State of Affairs With Regard to Thanatological Imaging in Francophone Sub-saharan Africa: Opinions of

Radiology Technicians. Med Imaging Radiol. 2021; 9:2. http://dx.doi.org/10.7243/2054-1945-9-2 